\title{
A REPERCUSSÃo dA CAUSA NA TEORIA do NEGócio JURÍDICO: UM PARALELO COM A FUNÇÃO SOCIAL DOS CONTRATOS
}

\author{
THE IMPACT OF THE CAUSE IN THE THEORY OF LEGAL ACTS: A \\ PARALLEL WITH THE SOCIAL FUNCTION OF THE CONTRACTS
}

Mariana Ribeiro Santiago *

Resumo: O presente artigo visa analisar a causa enquanto elemento do contrato no direito
comparado e sua repercussão no direito brasileiro, dentro do contexto do princípio da função
social dos contratos. Nesse intuito, partimos do estudo dos elementos do contrato na seara civil,
seguindo para a delimitação do instituto causa, diferenciando-o de figuras afins, culminando
com a confrontação entre as ideias de causa e função social dos contratos. O método de
abordagem adotado foi o dialético-jurídico, a par do procedimento de pesquisa bibliográfica.
Em conclusão, verificamos que, embora a causa não tenha sido adotada nacionalmente como
elemento do contrato, é possível se atingir os mesmos fins através da função social dos contratos.

Palavras-chave: Causa. Função social. Elementos. Contrato.

\begin{abstract}
The present paper analyses the cause as element of the contact in the comparative law and its repercussion in the brazilian law, within the context of the principle of the social function of the contracts. To that end, we start from studying the elements of the contract in the civil area, following to the delimitation to the institute "cause", differentiating it of the similar figures, culminating in the confrontation between the ideas of cause and social function of the contracts. The method of approach adopted was the dialectical legal, alongside the bibliographic research. In conclusion, we found that, although the cause has not been adopted nationally as an element of the contract, it's possible to reach the same finality through the social function of the contracts.
\end{abstract}

Keywords: Cause. Social function. Elements. Contract.

* Doutora em Direito Civil Comparado pela PUCSP. Professora da Universidade Nove de Julho Uninove. Editora-Chefe da Revista Thesis Juris.E-mail: mariana@nbsadvogados.com.br. 


\section{INTRODUÇC̃̃̃}

Nos negócios jurídicos, sob a perspectiva do seu conteúdo, é possível distinguir um regulamento de interesses e, materializada neste, uma razão típica, de ordem prática, que lhe é imanente. Trata-se do que a doutrina denomina como "causa", um interesse objetivo e socialmente verificável, ao qual o negócio deve corresponder (BETTI, 2008, p. 252).

O problema da causa é, no campo da dogmática, fonte de inúmeras e profundas divergências, envolvendo adeptos de todas as teorias sobre o negócio jurídico, havendo quem a aponte ora como elemento do ato (subjetivo ou objetivo), ora razão justificativa ou função, ora como algo existente de forma exterior ao ato, e, ainda, vinculando-a ou não aos negócios jurídicos em geral (RÁO, 1961, p. 100101).

Ocorre que, ao indicar os elementos do negócio jurídico no direito brasileiro, o atual Código Civil, em seu art. 104, diferentemente do que se observa em outros países quanto ao assunto, não enumera a causa ou sequer faz referência à existência de qualquer outro componente que não esteja ali elencado.

Da citada "omissão" por parte do Código Civil, questiona-se se o conceito de causa estaria banido do direito brasileiro e, ainda, qual a via aplicável, conforme o ordenamento jurídico nacional, visando à repressão ou sanção dos desvios observados na própria razão de ser do contrato, socialmente chancelada.

No intuito de se verificar a influência da ideia de causa no direito brasileiro, no que tange à seara negocial, no capítulo primeiro do presente trabalho analisaremos a definição e os elementos do negócio jurídico, após o que, no segundo capítulo, delimitaremos o conceito de causa e sua relação com figuras afins, e, por fim, no capítulo terceiro, traçaremos um paralelo em relação à função social do contrato.

Para a obtenção dos resultados almejados pelo trabalho, utilizamos a pesquisa bibliográfica, abrangendo obras especializadas, nacionais e estrangeiras, nas matérias negócios jurídicos e contratos. $\mathrm{O}$ método de abordagem seguido foi o dialético-jurídico, abrangendo o fenômeno, fato concreto e a teoria, de forma simultânea, buscando o resultado com o confronto entre os dois.

\section{NEGÓCIO JURÍDICO: DELIMITAÇÃO CONCEITUAL E ELEMENTOS CONSTITUTIVOS}

Como o Código Civil não define o que vem a ser negócio jurídico, embora indique os seus elementos constitutivos, restando aos estudiosos e aplicadores do direito se socorrerem da doutrina, à qual compete a função de conceituar e dissecar os institutos jurídicos. 
Na órbita do conceito de negócio jurídico, encontramos a questão do conflito entre a vontade interna e a vontade declarada do agente, tema sobre o qual a posição que cada autor adota interfere diretamente na definição por ele proposta.

A análise do mecanismo da atividade psíquica, em seus três estágios, mostra-se uma aliada na compreensão da atuação da vontade do negócio jurídico. Primeiramente os centros cerebrais recebem o estímulo do meio exterior (solicitação); depois, ponderam acerca das conveniências e resolvem como proceder (ponderação); e, por fim, reage a vontade à solicitação, levando ao mundo exterior o resultado deliberado (ação) (PEREIRA, 2004, p. 480-481).

O negócio jurídico atravessa fases similares. Por essa razão, há autores que identificam o negócio jurídico com a declaração de vontade,e outros que entendem não bastar uma declaração volitiva para gerá-lo, cabendo a apuração desse fator volitivo (PEREIRA, 2004, p. 480-481).

Em termos gerais, para os subjetivistas, encabeçados por Savigny, deve prevalecer, em todos os casos, a vontade interior do declarante; já os objetivistas consideram que a vontade declarada prepondera, mesmo fictícia, como forma de proteção à segurança nas relações privadas (AZEVEDO, 2008, p. 74-75).

Dentre os objetivistas, a definição comum de negócio jurídico é a de declaração de vontade - ou um complexo de declarações de vontade - capaz de criar, modificar ou extinguir relações na órbita do direito, visando a um fim protegido pelo ordenamento jurídico, pelo que se torna socialmente reconhecível (RUGGIERO, 1999, p. 315; BETTI, 2008, p. 88-89; TRABUCCHI, 1967, p. 147 e 159; MESSINEO, 1957, p. 460; LARENZ, 1978, p. 427-428; DIEZ-PICAZO, GULLÕN, 2000, p. 307; ALBALADEJO, 1958, p. 184-185; REALE, 2002, p. 203204; GOMES, 2010, p. 213; DINIZ, 2011, p. 472; AMARAL, 2008, p. 383). Em sentido diametralmente oposto, os subjetivistas sustentam ser o negócio jurídico primordialmente um ato de vontade (MONTEIRO, PINTO, 2009, p. 219-220; RODRIGUES, 1989, p. 10).

Entretanto, de acordo com Antonio Junqueira de Azevedo (2008, p. 82), as teorias subjetivista e objetivista apresentam um erro na sua formulação inicial, por admitirem a existência de dois elementos no negócio jurídico: a vontade e a declaração, divergindo somente quanto à prevalência de um e de outro, quando na verdade não há dois elementos, mas apenas um: a declaração de vontade.

Pelo entendimento do referido autor (AZEVEDO, 2008, p. 1-2), os subjetivistas se atêm à gênese do negócio, à vontade que lhe dá origem, e os objetivistas se prendem a sua função, ao caráter juridicamente vinculante de seus efeitos, em sua relação, enquanto norma, com outras normas, quando o correto seria se perquirir sobre a estrutura do negócio jurídico. 
A citada concepção estrutural do negócio jurídico se afasta das correntes voluntaristas porque não o investiga pela perspectiva psicológica, mas pela social, ou seja, não como ato de vontade, e, sim, como ato que é visto pela sociedade como apto a produzir efeitos jurídicos (AZEVEDO, 2008, p. 11).

Fora isso, na concepção estrutural não ficam esquecidos os efeitos dos negócios, mas estes não são analisados enquanto normas jurídicas concretas, presos a outras normas superiores, mas como relações jurídicas em sentido lato que o ordenamento atribui ao negócio, conforme pretendido pelas partes (AZEVEDO, 2008, p. 21).

Com base em tais premissas, Antônio Junqueira de Azevedo (2008, p. 16) afirma que

O negócio jurídico, estruturalmente, pode ser definido ou como categoria, isto é, como fato jurídico abstrato, ou como fato, isto é, como fato jurídico concreto. [...] Como categoria, é, pois, a hipótese normativa consistente em declaração de vontade(entendida esta expressão em sentido preciso, e não comum, isto é, entendida como manifestação de vontade, que, pelas suas circunstâncias, é vista socialmente como destinada à produção de efeitos jurídicos). [...] In concreto, negócio jurídico é todo fato jurídico consistente em declaração de vontade, a que o ordenamento jurídico atribui os efeitos designados como queridos, respeitados os pressupostos de existência, validade e eficácia impostos pela norma jurídica que sobre ele incide.

Acerca da posição adotada pelo direito brasileiro sobre o tema, pode-se dizer que esta é, em síntese, uma posição equilibrada, sendo que em cinco questões (declarações não sérias, simulação, interpretação, causa ilícita e erro) abre-se espaço para maior ou menor pesquisa da vontade interna, tendo a doutrina e jurisprudência se encarregado de diminuir os excessos que, nesses pontos, o Código Civil operou quanto à teoria da vontade (AZEVEDO, 2008, p. 116).

De fato, existem dispositivos do Código Civil que comprovam a influência da teoria da vontade no campo do erro e da interpretação dos negócios jurídicos, como o art. 112 ("Nas declarações de vontade se atenderá mais à intenção nelas consubstanciada do que ao sentido literal da linguagem") e o art. 144 ("O erro não prejudica a validade do negócio jurídico quando a pessoa, a quem a manifestação de vontade se dirige, se oferecer para executá-la na conformidade da vontade real do manifestante" $)$.

Passado esse introito sobre o conceito de negócio jurídico, importante se mostra o estudo dos elementos que o compõem. Quanto a esse tema, o art. 104, do Código Civil, determina que a validade do negócio jurídico requer: agente capaz (I), objeto lícito, possível, determinado ou determinável (II), e forma prescrita ou não defesa em lei (III). 
A análise dos elementos listados pela lei pode, contudo, variar conforme a posição filosófica que cada autor adota, pelo que seguiremos a classificação utilizada por Antônio Junqueira de Azevedo, exposta, em linhas gerais, a seguir, pois esta se encontra em perfeita consonância com a teoria tridimensional do direito (DINIZ, 2009) ${ }^{1}$.

Primeiramente, cabe enfatizar que a vontade não é elemento do negócio jurídico, sendo este somente a declaração de vontade, ou seja, cronologicamente, ele existe em face da declaração e todo o processo volitivo anterior não faz parte dele, embora seja resultado do processo volitivo interno. A vontade pode, assim, influenciar a validade ou a eficácia do negócio, mas, como aspecto do querer, ela não integra, existencialmente, o negócio jurídico, ficando inteiramente absorvida pela declaração, seu resultado (AZEVEDO, 2008, p. 82).

Antônio Junqueira de Azevedo (2008, p. 30) analisa o negócio jurídico por meio de três planos: o da existência, o da validade e o da eficácia, sendo que o negócio precisa de elementos, para existir; de requisitos, para ser válido; de fatores de eficácia, para ser eficaz. Analisaremos cada um dos referidos planos a seguir.

No plano da existência dos negócios jurídicos, verificamos: a) elementos gerais, comuns a todos os negócios (intrínsecos e extrínsecos); b) elementos categoriais, próprios de cada tipo de negócio, resultando diretamente de indicação da ordem jurídica (essenciais ou inderrogáveis e naturais ou derrogáveis); c) elementos particulares, que existem em um negócio determinado, por vontade das partes (AZEVEDO, 2008, p. 32, 35 e 38).

Elementos gerais intrínsecos são: a) forma (escrita, oral, mímica, silêncio etc.); b) objeto (o conteúdo); e c) circunstâncias negociais (o que resta da declaração de vontade, excluindo-se a forma e o objeto, o conjunto de circunstâncias que compõem um padrão social pelo qual uma manifestação de vontade é reconhecida

1 Segundo Miguel Reale (2002, p. 64-65), “uma análise em profundidade dos diversos sentidos da palavra direito veio demonstrar que eles correspondem a três aspectos básicos, discerníveis em todo e qualquer momento da vida jurídica: um aspecto normativo (o direito como ordenamento e sua respectiva ciência); um aspecto fático (o direito como fato, ou em sua efetividade social e histórica) e um aspecto axiológico (o direito como valor de Justiça)", sendo que esse aspecto de tridimensionalidade ensejou a criação da teoria tridimensional do direito, pela qual se sustenta que: “a) onde quer que haja um fenômeno jurídico, há, sempre e necessariamente, um fato subjacente (fato econômico, geográfico, demográfico, de ordem técnica etc.); um valor, que confere determinada significação a esse fato, inclinando ou determinando a ação dos homens no sentido de atingir ou preservar certa finalidade ou objetivo; e, finalmente, uma regra ou norma, que representa a relação ou medida que integra um daqueles elementos ao outro, o fato ao valor; b) tais elementos ou fatores (fato, valor e norma) não existem separados um dos outros, mas coexistem numa unidade concreta; c) mais ainda, esses elementos ou fatores não só se exigem reciprocamente, mas atuam como elos de um processo (já vimos que o direito é uma realidade histórico-cultural) de tal modo que a vida do direito resulta da interação dinâmica e dialética dos três elementos que a integram". 
socialmente como destinada à produção de efeitos jurídicos) ${ }^{2}$. Os elementos gerais extrínsecos, pressupostos, ou seja, preexistentes ao negócio, são: a) tempo;b) lugar; e c) agente, lembrando serem os dois primeiros comuns a todo fato jurídico, e o último, ao ato jurídico em sentido amplo (AZEVEDO, 2008, p. 32-33 e 122) ${ }^{3}$.

Já os elementos categoriais essenciais ou inderrogáveis definem cada categoria de negócio (compra e venda, doação, depósito, comodato, mútuo etc.), caracterizando sua essência ${ }^{4}$; enquanto os elementos categoriais naturais ou derrogáveis, mesmo defluindo da natureza do negócio, podem ser afastados pela vontade das partes, sem que se altere o tipo do negócio (AZEVEDO, 2008, p. 35).

No tocante aos elementos particulares ${ }^{5}$, estes são em número indeterminado, em virtude de decorrerem da vontade das partes, num determinado caso concreto. Todavia, três exemplos se destacam, pela frequência com que se apresentam: a) a condição - subordina os efeitos do negócio jurídico a evento futuro e incerto; b) o termo - subordina os efeitos do negócio jurídico a evento futuro e certo; e c) o encargo - restringe uma liberalidade (AZEVEDO, 2008, p. 38).

Em conclusão, pode-se afirmar que, no plano da existência, a supressão de qualquer elemento essencial ocasiona a inexistência do negócio. Já na ausência de um elemento categorial inderrogável, o ato não existe como negócio daquele tipo, havendo a possibilidade de configurar-se negócio de outro tipo (conversão substancial $\left.^{6}\right)($ AZEVEDO, 2008, 34-35 e 40). Os elementos categoriais derrogáveis

2 Antônio Junqueira de Azevedo (2008, p. 123) lembra que "é justamente, a pouca familiaridade de certas pessoas com os padrões culturais de uma sociedade, isto é, a deficiente assimilação dos modelos culturais de atitudes jurídicas por parte de certas pessoas, como os índios, que leva o ordenamento jurídico a considerar nulos os atos por eles realizados dentro dos padrões da sociedade que não é a sua, mas válidos os atos por eles realizados dentro de seu próprio ambiente social, através de modelos culturais dos quais têm pleno conhecimento".

3 Conforme Antônio Junqueira de Azevedo (2008, p. 34), "se faltarem os elementos tempo ou lugar, não há sequer fato jurídico; sem agente, poderá haver fato, mas não ato jurídico”.

4 Para Antônio Junqueira de Azevedo (2008, p. 36), "são exemplos de elementos categoriais naturais: a responsabilidade pela evicção, na compra e venda e nos contratos onerosos de disposição de bens; a responsabilidade pelos vícios redibitórios, nos contratos comutativos; a gratuidade, no depósito, no mútuo e no mandato etc.".

5 Vale ressaltar que Antônio Junqueira de Azevedo (2008, p. 39) inclui a cláusula penal como elemento particular dos negócios jurídicos, entendimento do qual Maria Helena Diniz (2009) discorda, por considerar que se trata de sanção pelo inadimplemento.

6 De acordo com Antônio Junqueira de Azevedo (2008, p. 66 e 69), “tanto dentro de cada plano quanto nas relações entre um plano e outro há um princípio fundamental que domina toda a matéria da inexistência, invalidade e ineficácia; queremos referir-nos ao princípio da conservação. Por ele, tanto o legislador quanto o intérprete, o primeiro, na criação das normas jurídicas sobre os diversos negócios, e o segundo, na aplicação dessas normas, devem procurar conservar, em qualquer um dos três planos 
e os particulares podem estar ausentes do negócio pela vontade das partes sem que este se descaracterize.

Passemos, então, à análise do segundo plano do negócio jurídico, em que investigaremos os seus requisitos de validade.

Os requisitos são aqueles caracteres que devem estar presentes nos elementos do negócio para que este seja válido. Há, nesse ponto, um paralelismo entre o plano da existência e o plano da validade, pois o primeiro é um plano de substâncias; o segundo, um plano de adjetivos, de qualidades que os elementos devem ter (AZEVEDO, 2008, p. 42).

Assim, como os requisitos são qualidades dos elementos, a declaração de vontade, tomada primeiramente como um todo, deve ser: a) resultante de um processo volitivo; b) querida com plena consciência da realidade; c) escolhida com liberdade; d) deliberada sem má-fé (AZEVEDO, 2008, p. 42-43).

Entretanto, se os elementos gerais intrínsecos são objeto, forma e circunstâncias negociais, tem-se que o objeto deverá ser lícito, possível e determinado ou determinável; a forma será livre ou aquela prescrita em lei; e as circunstâncias negociais não têm requisitos exclusivamente seus, já que são o elemento caracterizador da essência do próprio negócio, aquele quid que qualifica uma manifestação, transformando-a em declaração (AZEVEDO, 2008, p. 43).

Quanto aos requisitos ligados aos elementos gerais extrínsecos, pode-se dizer que: a) o agente deverá ser capaz e, conforme o caso, legitimado para o negócio; b) o tempo, se o ordenamento jurídico impuser que o negócio se faça em um determinado momento, deverá ser o tempo útil; c) o lugar, se, excepcionalmente, tiver algum requisito, há de ser o lugar apropriado (AZEVEDO, 2008, p. 43).

\footnotetext{
- existência, validade e eficácia -, o máximo possível do negócio jurídico realizado pelo agente. [...] O princípio da conservação consiste, pois, em se procurar salvar tudo que é possível num negócio jurídico concreto. [...] No plano da existência, é, naturalmente, indispensável que se encontrem, no negócio, os elementos gerais, para considerá-lo como existente; essa regra não sofre exceção. Uma vez, porém, que o negócio exista, se acaso lhe faltar um elemento categorial inderrogável (ou, se, para evitar que o negócio seja considerado inválido ou ineficaz, se puder dar como inexistente um elemento categorial inderrogável), abre o ordenamento jurídico a possibilidade, para o intérprete, de convertê-lo em negócio de outro tipo, mediante o aproveitamento dos elementos prestantes; é a conversão substancial. [...] A nulidade de forma pode acarretar a conversão formal, que torna válido o negócio, graças à adoção de uma forma menos rigorosa que a escolhida pelas partes. Além disso, pode-se observar uma tendência legislativa a admitir ‘correções' dos negócios jurídicos, em casos de erro e de lesão, os quais, se não fosse a correção, levariam à anulação". Todavia, a conversão não se confunde com a convalidação. Conforme Antônio Chaves (1982, p. 1498), "ratificação, confirmação, validação ou convalidação é o ato receptício pelo qual uma pessoa tem por bons os atos praticados com irregularidades que possam dar margem a uma eventual anulabilidade, abrindo mão, por essa forma, de qualquer possibilidade de invocá-la".
} 
Acercados elementos categoriais, somente os inderrogáveis apresentam requisito, qual seja, as partes, ao escolherem determinado tipo de negócio, deverão seguir o regime jurídico estabelecido para ele, por exemplo, o preço é elemento categorial inderrogável na compra e venda, e tem como requisitos o ser determinável, justo e verdadeiro, não sendo possível que seja definido apenas por uma das partes (AZEVEDO, 2008, p. 43 e 45).

Em relação aos requisitos afetos aos elementos particulares, cabe afirmar que as condições são atingidas por dois tipos diferentes de falta dos requisitos de validade: as condições que vitiantur et vitiant ${ }^{7}$, contaminando de nulidade todo o negócio, como as juridicamente impossíveis, as ilícitas, as meramente potestativas, as perplexas ou contraditórias etc.; e as que vitiantur sed non vitiant ${ }^{8}$, cujo evento consiste em fato fisicamente impossível e as de não fazer coisa impossível. $O$ termo também tem requisitos, como, vitiantur et vitiant, o colocado em actus legitimi ${ }^{9}$. E o encargo não escapa às exigências de requisitos, não podendo ser ilícito ou impossível, sob pena de nulidade, preservando-se, contudo, o ato de liberalidade (vitiantur sed non vitiant) (AZEVEDO, 2008, p. 46-48).

Em tempo: se verificados os elementos do negócio, mas faltar um requisito nele exigido, o negócio existe, mas não é válido, é nulo ou anulável (AZEVEDO, 2008, p. 63).

Por derradeiro, o terceiro plano a se analisar o negócio jurídico é o da eficácia, no qual não se trata, naturalmente, de toda e qualquer possível eficácia prática do negócio, mas apenas a jurídica e, especialmente, a própria ou típica, ou seja, referente aos efeitos manifestados como queridos (AZEVEDO, 2008, p. 49).

Podemos distinguir três fatores de eficácia: a) os de atribuição da eficácia em geral, sem os quais o ato praticamente nenhum efeito produz (como nos casos de condição suspensiva ${ }^{10}$ ); b) os de atribuição da eficácia diretamente visada,

\footnotetext{
7 É viciada e vicia (tradução livre).

8 É viciada, mas não vicia (tradução livre).

9 Ato legítimo. Ex.: casamento.

${ }^{10}$ De acordo com Vicente Ráo (1961, p. 298-299), “a condição alcança e atinge os efeitos dos atos
} jurídicos porque assim o quer a vontade dos agentes, ou partes. Não é uma cláusula acessória como pensam alguns juristas, pois o ato condicional como um só todo se apresenta, ou seja, como unidade que se não pode partir em declaração principal e declaração acessória de vontade. [...] A condição não se presume - pois a sujeição dos efeitos dos atos jurídicos a alguma condição só da vontade dos agentes ou partes depende, quem a invoca deve prová-la: conditio non praesumitur. Na dúvida, ou na falta de prova, presume-se, sim, que o ato seja puro, isto é, não condicional. [...] Entre as diferentes espécies de condições figuram, como de maior importância, as suspensivas e resolutivas[...]. Suspensiva é a condição que subordina o início da eficácia do ato jurídico à verificação ou não verificação de um evento futuro e incerto (sub condicione stipulatiofit cum 
indispensáveis para que um negócio já eficaz entre as partes produza exatamente os efeitos por ele visados (o negócio realizado entre o mandatário sem poderes e o terceiro, por exemplo, produz efeitos entre eles, mas não os efeitos diretamente visados); c) os de atribuição de eficácia mais extensa, indispensáveis para que um negócio plenamente eficaz dilate seu campo de atuação, tornando-se oponível a terceiros (é o que se observa nos casos de registro) (AZEVEDO, 2008, p. 57).

Dessa forma, observando-se os elementos e os requisitos do negócio jurídico, mas ausente um fator de eficácia, o negócio existe e é válido, mostrando-se, contudo, ineficaz (ineficácia em sentido restrito) (AZEVEDO, 2008, p. 63).

Ressalve-se, no entanto, que o negócio existente, válido e eficaz pode, por causa superveniente, tornar-se ineficaz, ocasionando a sua resolução, como, por exemplo, nos casos de implemento de condição resolutiva, onerosidade excessiva etc., configurando-se, nesse passo, fatores de ineficácia (AZEVEDO, 2008, p. 60-61).

Em verdade, a exposição procedida retro consiste numa apertada síntese do entendimento de Antônio Junqueira de Azevedo sobre os elementos do negócio jurídico, o qual endossamos, valendo ressaltar que este autor enumera casos excepcionais de negócios válidos e ineficazes e outros nulos e eficazes ${ }^{11}$.

Todavia, a enumeração dos componentes do negócio jurídico acima realizada, utilizada, em uníssono, no direito nacional, discrepa do entendimento adotado por algumas legislações estrangeiras, as quais agregam à tal lista o conceito de causa, o qual analisaremos a seguir.

\section{A CAUSA DO NEGócio JURÍDICO}

À enumeração dos elementos do negócio jurídico observada no art. 104, do Código Civil brasileiro, citado anteriormente, agregam o elemento "causa" os códigos civis da França (Art. 1.108. "L'obligation sans cause, ou sur une fausse

\footnotetext{
aliquem casum differtur obligatio. Inst., III, 15, 4).[...] Resolutiva é a condição cujo implemento faz cessar os efeitos do ato jurídico [...]. [...] Os romanos não estabeleciam essa distinção. Para eles toda condição era suspensiva. Dos contratos que nós consideramos sujeitos à condição resolutiva, os jurisconsultos romanos diziam serem, em si mesmos, contratos puros e simples, sendo apenas a sua resolução submetida a uma condição suspensiva: ULPIANO, aludindo à venda feita sob essa modalidade, declarava tratar-se de pura emptio, quae sub condicione resolvitur (DXVIII, 22 )".

11 Feita essa advertência, ressaltamos que a situação normal é a da eficácia dos atos válidos, mas existem duas situações excepcionais: a eficácia do nulo e a ineficácia do válido. Exemplo clássico de ato nulo eficaz é o do casamento putativo, que tem "eficácia civil", em relação ao cônjuge de boa-fé (ou aos dois se ambos estavam de boa-fé) e em relação aos filhos. Já como exemplos de atos válidos e ineficazes, tem-se o ato sob condição suspensiva e o ato praticado pelo representante sem poderes, como o negócio feito pelo mandatário, agindo fora dos limites do mandato. Ocorrendo a ratificação, o negócio adquire sua eficácia própria; essa ratificação é, pois, fator de eficácia (AZEVEDO, 2008, p. 49, 53, 55-56).
} 
cause, ou sur une cause illicite, ne peut avoir aucun effet" ${ }^{12}$ e da Itália (Art. 1.325. "Indicazione dei requisiti. I requisiti del contratto sono: 1) l'accordo delle parti [...]; 2) la causa [...]; 3) l'oggetto [...];4) la forma, quando risulta che è prescritta dalla legge sotto pena di nullità" $)^{13}$.

Ao comentar o citado dispositivo do Código francês, Jean Carbonnier (2004, p. 2017) afirma que é uma condição essencial para a validade do contrato que qualquer parte que se obrigue através dele o faça por uma causa lícita. $O$ Código francês não define o termo causa e há polêmica na doutrina, sendo que o acordo parece estar na afirmação de que a palavra tem diferentes acepções, com implicações distintas. Opõem-se, assim, causa abstrata e concreta, a objetiva e a subjetiva, causa da obrigação e a do contrato, bem como as imediatas e as móveis.

De fato, a corrente causalista possui diversas orientações, as quais José de Oliveira Ascensão (2010, p. 254-255) classifica em três teorias: a) a subjetiva, que identifica a causa com o motivo do agente, a impeli-lo em todos os atos daquele tipo; b) a objetiva, pela qual a causa é a função econômico-social típica de uma categoria de negócio, o seu "para quê"; e c) a eclética, a qual defende a função objetiva representada no espírito do agente, no seu processo volitivo, como motivo típico.

Ainda conforme o referido autor (ASCENSÃO, 2010, p. 255-256),

As correntes anticasualistas exprimem uma ordem formalista, hoje em grande relevo com a onipotência do mercado e o relativismo dominante. $O$ que é necessário é que o sistema funcione, seja à custa do que for", e já as correntes casualistas "estão associadas a uma intenção de controle objetivo e de intervenção social. São menos liberais e não aceitam a tutela do tráfego como um valor absoluto.

A causa, segundo Emilio Betti (2008, p. 252), é um interesse objetivo e socialmente verificável, ao qual o negócio deve corresponder. Em termos análogos, Alberto Gosson Jorge Júnior (2013, p. 73-74) identifica a causa, em seu sentido objetivo, com o "fim prático-social ou a razão econômico-social do contrato", para concluir que "se constitui propriamente num requisito e sua inobservância acarretará ou a invalidade ou a ineficácia da obrigação".

Para Roberto de Ruggiero (2009, p. 360), a causa é

12 Art. 1.108. "A obrigação sem causa, ou sobre uma falsa causa, ou sobre uma causa ilícita, não pode ter nenhum efeito" (tradução livre).

${ }^{13}$ Art. 1.325. "Indicação dos requisitos. Os requisitos do contrato são: 1) o acordo das partes [...]; 2) a causa $[\ldots]$; 3) o objeto [...]; 4) a forma, quando prescrita pela lei sob pena de nulidade" (tradução livre). 
O fim econômico e social reconhecido e garantido pelo direito; é a própria função do negócio objetivamente considerado, a condição que justifica a aquisição excluindo o fato de ser lesiva do direito alheio e que, de certo modo, representa a vontade da lei face à vontade privada. Do que se diz resulta claramente que (exceto os negócios abstratos, que por si não exprimam uma causa e por isso podem acolher várias e diversas) todo o tipo de negócio tem uma causa própria, correspondente à sua função específica, uma causa que lhe dá feição e caráter e justifica o seu reconhecimento.

Trata-se, conforme o referido autor (RUGGIERO, 2009, p. 364-365), de um conceito unitário, embora os vários tipos de negócios possuam deferentes aspectos práticos e específicos, como a guarda da coisa no comodato e no depósito, a troca de duas coisas na permuta, o gozo de uma coisa mediante remuneração na locação etc.

Manuel Albaladejo (1958, p. 202) entende que o direito espanhol acolhe o conceito objetivo de causa, pelo que esta é

El fin inmediato y objetivo a que la atribución se dirige; porque la atribución es un mero medio de alcanzar aquel fin; es decir, no tiene su justificación en ella misma. No se realiza sólo por enriquecer, sino que se enriquece por algo. Como resultado inmediato, la atribución produce un enriquecimiento al que la recibe, y la razón o fin de este enriquecimiento, es la causa de aquélla.

Vicente Ráo (1961, p. 100-101), ao definir o ato jurídico como "declaração dispositiva e preceptiva da vontade, dirigida direta e imediatamente à consecução dos resultados práticos, individuais e sociais, produzidos pelos efeitos que o ordenamento lhe confere", considera que aquilo que se pretende delinear como causa do ato não seria elemento, requisito ou quid a integrar o seu conceito.

Apesar dessa obscuridade conceitual, parte da doutrina defende que não se pode eliminar dos negócios jurídicos o conceito de causa, pois do contrário não se teria fundamento próprio para invalidá-los quando desviados de sua função típica (GOMES, 2002, p. 54-55; CIFUENTES, 1986, p. 179-190).

De acordo com a moderna teoria da causa, cada contrato tem uma função econômica específica, típica, caracterizadora. E, considerando-se tal variedade, essas funções econômicas típicas podem ser: promover a circulação de riquezas; colaboração; prevenção de risco; conservação e cautela; prevenção de controvérsias; concessão de crédito; ou constituição de direitos reais de gozo ou de garantia (esse caso não se aplica no regime brasileiro, tendo em vista que no ordenamento jurídico pátrio o contrato não tem o condão de constituir direitos reais) (GOMES, 2002, p. 19-21). 
A doutrina classifica como principais funções econômicas dos contratos: a) a de troca, quando se modifica a titularidade de uma coisa ou de um direito, promovendo a circulação de bens, inclusive no caso dos contratos gratuitos; b) a de crédito, no caso dos contratos que visam à circulação de dinheiro conferindo crédito, como no mútuo e nos contratos bancários em geral; c) a de garantia, se se pretende dar uma segurança a respeito do cumprimento de outro contrato, fortalecendo o direito do credor, como no caso da fiança, do penhor e da hipoteca; d) a de custódia, quando visam à entrega de coisa a outrem, a quem cabe a guarda e conservação desta. O depósito é o exemplo clássico; e) a laboral, que se observa no contrato de trabalho e variações, como a locação de serviços, mandato mercantil, comissão e factoring; f) a de previsão, no caso de contratos destinados à prevenção de riscos, como no contrato de seguro; g) a de recreação, na hipótese dos contratos que têm finalidade de entretenimento e lazer, como nos contratos de turismo, jogos de azar, rifas etc.; h) a de cooperação, que é comum em quase todos os contratos, onde se observa um estreitamento dos laços entre os contratantes, que se auxiliam numa tarefa, como no contrato de sociedade, no consórcio de empresas etc.; e i) a de solução de controvérsias, que visa pôr fim em litígios surgidos entre as partes, a exemplo do que ocorre na transação e no acordo arbitral (LORENZETTI, 1999, p. 26-27; SANTOS, 2002, p. 114-116; ALTERINI, 1999, p. 184).

Antônio Junqueira de Azevedo (2008, p. 149-150) ressalta a importância de não se confundir causa com elemento categorial inderrogável objetivo, pois este repercute no plano da existência do negócio jurídico. Conforme o autor, "a causa é um fato externo ao negócio, mas que o justifica do ponto de vista social e jurídico, enquanto o elemento categorial objetivo é justamente a referência, que se faz a esse fato, no próprio conteúdo do negócio".

E continua o referido autor (AZEVEDO, 2008, p. 150): “por outras palavras, o elemento inderrogável objetivo faz parte, isto é, é integrante da estrutura do negócio, e a causa, não. [...] É o elemento categorial, e não a causa, que fixa o regime jurídico a que o negócio obedece".

Para exemplificar o seu pensamento, Antônio Junqueira de Azevedo (2008, p. 150) usa o caso da compra e venda. Na referida espécie contratual, caracterizada, em regra, pelo consenso em entregar uma coisa mediante um preço, não se nota a importância na distinção entre o elemento categorial e a causa. No entanto, ao se imaginar a compra e venda não com a função de circulação de bens, mas de garantia, como no caso da venda com pacto de retrovenda, percebe-se que houve uma mudança de função, mas esta alteração de causa não repercute no regime jurídico deste contrato, que continua a ser o da compra e venda. 
De fato, na hipótese de mudança de função do negócio, o legislador pode criar um tipo contratual próprio, que atenda as peculiaridades do caso, como se observou, por exemplo, nos contratos de alienação fiduciária em garantia. Pode-se dizer, assim, que, embora a causa não influencie diretamente o regime de cada negócio concreto, pode repercutir na atividade legislativa (AZEVEDO, 2008, p. 150-151).

Segundo Roberto de Ruggiero (1999, p. 364-365),

Menos verdadeiro ainda é que a causa se confunda com o objeto ou com o consenso: a causa, no contrato bilateral, é a relação entre as duas prestações, a troca de um valor por outro ou, mais sinteticamente, a própria bilateralidade e não qualquer das simples prestações consideradas em si; a causa nos unilaterais é a prévia prestação recebida ou o fim a que a prestação tende e não a própria prestação; a causa nos contratos gratuitos é o espírito de beneficiar alguém, que justifica uma atribuição patrimonial sem contrapartida, e este espírito de liberalidade, este animus donandi, assim como não se confunde com os motivos individuais (doa-se para remunerar um serviço, para se cativar o ânimo do donatário, por mera ostentação), também não se confunde nem se identifica com o consenso, de que é independente e distinto e, tanto, que pode existir o consenso e faltar ou ser ilícita a causa da liberalidade.

Deve-se diferenciar também causa da obrigação e do contrato. A primeira é a fonte donde surge o vínculo, no que se inclui os contratos; a segunda reside na essência do contrato considerado em todo o seu conjunto (RUGGIERO, 1999, p. 365-366).

A causa objetiva dos contratos distingue-se, ainda, dos motivos que levaram as partes a contratarem, do ponto de vista de que leva em consideração o processo econômico e não a vontade específica de cada contratante em particular, de caráter subjetivo (LORENZETTI, 1999, p. 23-24; AZEVEDO, 2008, p. 153), distinção esta com repercussão inclusive em temas como o revisionismo contratual e imprevisão (FIÚZA, 2009, p. 404).

Por outro lado, o Código Civil de 1916, por uma imprecisão técnica, determinava, no seu art. 90, que "só vicia o ato a falsa causa, quando expressa como razão determinante ou sob a forma de condição", utilizando o termo "causa" com significado de "motivo".

Nas palavras de Emilio Betti (2008, p. 257-258),

Os motivos simplesmente individuais não são elementos constitutivos da causa. Precisamente por serem individuais, eles são essencialmente subjetivos e internos, contingentes, variáveis, multíplices, diversos, e, com frequência, até contraditórios. Como tais, eles são imponderáveis e, diferindo disso na causa, não comportam uma valoração social positiva, enquanto não passarem a fazer parte do conteúdo do negócio: continuam, portanto, a ser irrelevantes também para o direito. 
Sobre a distinção entre causa e motivo do negócio jurídico, Caio Mário da Silva Pereira (2004, p. 504-505) pondera que

\begin{abstract}
Os motivos que levam o agente a praticá-lo podem ser vários, todos interligados, mais ou menos indissoluvelmente: o médico aconselha uma pessoa a mudar de clima em benefício de sua saúde; o cliente planeja passar suas férias numa estância hidromineral; delibera vender um terreno para obter numerário; realiza um contrato de compra e venda. Há uma corrente de motivos, todos tendente a um mesmo fim, ligados por uma causação subjetiva, de que a declaração de vontade é o desfecho. [...] Na pesquisa das razões determinantes dos negócios jurídicos é necessário fazer uma distinção fundamental, que consiste em destacar a causa do ato, dos motivos que levaram o agente a praticá-lo. Tais motivos se apresentam como uma razão ocasional ou acidental do negócio, e nunca faltam como impulso originário, mas não têm nenhuma importância jurídica. Por isso, o jurista deve relegá-los para o plano psicológico, a que seria então afeta a indagação da deliberação consciente. E detém-se apenas na investigação da causa propriamente dita, que se deve caracterizar na última das razões determinantes do ato.
\end{abstract}

No mesmo sentido, César Fiúza (2009, p. 404-405) ensina que

Motivo é razão intencional determinante do contrato. O motivo é irrelevante, salvo disposição expressa em sentido contrário, no contrato. [...] Karl Larenz dá o exemplo da pessoa que adquire alianças de noivado, e este vem a ser cancelado. O motivo da compra era o noivado. Ocorre que, por não ser de nenhum interesse para o vendedor, este motivo não poderia interferir no contrato. Uma vez cancelado o noivado, o contrato deverá ser cumprido, ainda assim. [...] Não se confunde com a causa, que é a razão de ser jurídica do contrato. $\mathrm{O}$ motivo é interno, varia de pessoa para pessoa.

No Código Civil atual, a citada imprecisão sobre o termo "causa" foi devidamente corrigida, clarificando, ainda mais, a diferença entre as duas noções. Pode-se ler, no art. 140, o qual trata da questão versada no referido art. 90, do Código de 1916, que "o falso motivo só vicia a declaração de vontade quando expresso como razão determinante".

Em verdade, a causa, assim como a vontade das partes, não é elemento do negócio jurídico, mas detém grande importância para a validade e eficácia dos mesmos, caso se trate, respectivamente, de causa pressuposta ou causa final, inclusive nos ordenamentos estrangeiros (AZEVEDO, 2008, p. 152).

Sobre o aspecto do direito comparado, Antônio Junqueira de Azevedo (2008, p. 154) ensina que

A doutrina francesa encara a ideia de causa sob o ângulo da validade, em virtude dos próprios termos do art. 1.108, enquanto, na doutrina alemã, a ideia de causa é antes vista como influenciando a eficácia do negócio jurídico. De resto, sob a égide do BGB, que não se refere à causa, a doutrina alemã restringe a ideia de causa aos negócios jurídicos patrimoniais e, mais especificamente, aos negócios de atribuição. 
No Brasil, a legislação civil adotou a corrente anticausalista, sem fazer referência expressa ao tema da causa no que tange aos elementos do negócio jurídico, de forma similar à Alemanha, Suíça, Áustria e Portugal (PEREIRA, 2004, p. 508).

Pari passu, a questão acerca da causa dos negócios jurídicos no ordenamento nacional acaba surgindo na distinção entre negócios causais dos abstratos, ou quando o legislador utiliza a expressão "justa causa" nesse âmbito, bem como nas hipóteses de resolução contratual por inadimplemento, nos contratos bilaterais, embora não seja expressamente alçada à categoria de requisito na lei civil (AZEVEDO, 2008, p. 154 e 157).

\section{PERSPECTIVAS PARA ANÁlise dA CAUSA E DA FUNÇÃo SOCIAL DOS CONTRATOS NO DIREITO BRASILEIRO}

Considerando que o Brasil adotou, quanto à definição dos elementos do negócio jurídico, a corrente anticausalista, pela qual a causa não integra a estrutura do pacto, não se poderia afirmar, consequentemente, conforme o ordenamento pátrio, a invalidade com lastro em tal argumento.

Ao analisar o aludido quadro, Caio Mário da Silva Pereira (2004, p. 508) assevera que no Direito Civil pátrio é possível se atingir a mesma finalidade que se pretende pela regulamentação da causa como elemento do negócio jurídico através da invalidade por ilicitude de objeto ou pelo desvio da função social do contrato.

A identificação entre causa e objeto do negócio aparece também na obra de Washington Monteiro de Barros (MONTEIRO; PINTO, 2009, p. 211), para quem "causa é parte integrante do ato de vontade, confunde-se com o próprio escopo do ato. Assim, quando se diz que a causa ilícita vicia o ato jurídico, é porque o próprio objeto dele é ilícito".

Em sentido oposto, Alberto Gosson Jorge Júnior (2013, p. 72) entende que

A causa do contrato não se confunde com o seu objeto. $O$ objeto do contrato não é a prestação nem o objeto desta. A prestação é o objeto da obrigação, e este tanto pode ser a entrega de uma coisa como o exercício de uma atividade ou a transmissão de um direito. Objeto do contrato é o conjunto de atos que as partes se comprometeram a praticar, singularmente considerados, não no seu entrosamento finalístico ou, por outras palavras, as prestações das partes, não o intercâmbio entre elas, pois este é a causa.

Quanto à comparação do elemento causa com a ideia de invalidade por ilicitude do objeto, consideramos que caracterizam campos diversos, sendo a primeira noção muito mais abrangente, pelo que não se poderia afirmar ser possível substituí-la satisfatoriamente pela segunda. 
Já em relação à proximidade entre os institutos da causa e da função social, há certamente um grande número de pontos convergentes entre os mesmos que justifica a afirmação de que esta supre, na prática, a inclusão daquela como elemento do negócio jurídico no ordenamento jurídico brasileiro, embora os contratos sejam uma espécie do gênero negócio jurídico.

Segundo o art. 421, do Código Civil, "a liberdade de contratar será exercida em razão e nos limites da função social do contrato". Como tal artigo não define a expressão "função social do contrato", cabe à doutrina precisar o significado desse instituto. Trata-se, fora de dúvida, de tarefa árdua, em decorrência, inclusive, do alto teor axiológico inerente ao tema.

Segundo Norberto Bobbio (apud SANTOS, 2002, p. 103), numa analogia entre a sociedade e o organismo humano, função é a "prestação continuada que um determinado órgão dá para a conservação e desenvolvimento, segundo um ritmo de nascimento, crescimento e morte, de todo o organismo, é dizer, do organismo considerado como um todo", de onde se infere a ideia principal de que o poder individual deve ser exercido em proveito de um sistema maior, do conjunto.

De Plácido e Silva (1963, p. 722-723), define função (do latim, fungi), em termos gerais, como o direito ou dever de agir, atribuído por lei a uma pessoa, para assegurar o preenchimento de uma missão.

Já a palavra "social", como assinala Paulo Bonavides (1972, p. 203-204), é de grande imprecisão semântica, estando, por isso, sujeita a inúmeras variações de sentido, ao sabor inclusive de determinados preconceitos ideológicos. Esse fator, sem dúvida, dificulta a tarefa de conceituação.

No conceito de J. W. Hedemman (1958, p. 26), a palavra social significa "el punto de partida ideológico de la contraposición entre pobres y ricos o, como frecuentemente se dice en la literatura científica, entre los que tienen bienes y los desheredados".

Jefferson Carús Guedes (2003, p. 351), em obra que trata da evolução da funcionalidade primitiva para o atual conceito de função social, afirma que a expressão "função social" significa, abreviadamente, utilidade à sociedade, atendimento ao interesse coletivo.

Em obra datada de 1973, Jefferson Daibert (1973, p. 19) já se referia a uma função social do contrato, numa concepção, entretanto, que não a identifica como uma limitação da autonomia privada, conforme é a tendência moderna.

De acordo com o autor (DAIBERT, 1973, p. 19), da mesma forma que o direito tem uma função eminentemente social por disciplinar a vida em sociedade, dando-lhe as normas de direito positivo, o contrato também tem função social 
similar e de alta relevância, a partir do momento em que aproxima os homens para que transijam harmonicamente, sendo fator preponderante no comércio e na vida privada.

Atualmente, na definição de função social do contrato, a totalidade dos autores por nós analisados ressalta o caráter condicionador de tal princípio, que submete o interesse privado ao interesse público, limitando, assim, a autonomia privada.

Antonio Junqueira de Azevedo (1998, p. 116-117) afirma que o preceito da função social dos contratos objetiva integrar os contratos numa ordem social harmônica, impedindo que prejudiquem a coletividade ou mesmo pessoas determinadas. Na sua concepção, o princípio implica na proibição de se ver o contrato como um átomo que somente interessa às partes. Qualquer contrato passa a ter, assim, importância para toda a sociedade.

Gino Gorla (1959, p. 244), ao tratar da teoria da função social do contrato, explica que

Un contrato que se dirija a realizar intereses fútiles, caprichosos, que no representen ningún interés para la sociedad o ninguna 'utilidad social', un contrato 'socialmente fútil o improductivo' no sería digno del reconocimiento jurídico, sino que sería jurídicamente indiferente.

O citado autor (GORLA, 1959, p. 244), exemplifica, afirmando que, por essa teoria, por exemplo, não mereceria amparo jurídico o contrato celebrado entre vizinhos para que um venha saudar o outro à porta de sua casa todas as manhãs, ou o contrato em que uma das pessoas se obriga a jogar uma partida de golfe etc.

Na mesma linha de pensamento, Orlando Gomes (2002, p. 20) assevera que pelo princípio da função social do contrato entende-se dever ser o contrato socialmente útil, gerando o interesse público na sua tutela. Consequentemente, os contratos que regem interesses sem utilidade social, fúteis ou improdutivos não merecem proteção jurídica.

O mesmo autor (GOMES, 1967, p. 8), em obra diversa, defende ainda que a atribuição da "função social ao contrato alarga a esfera da responsabilidade para apanhar as situações nas quais, em razão de ter sido concluído, prejudica terceiros".

Na lição de Álvaro Villaça (2002, p. 29), o art. 421, do Código de 2002, alarga a capacidade do juiz para proteger o mais fraco na contratação, no caso de estar sofrendo pressões em decorrência da hipossuficiência econômica, o que decorre, por exemplo, da imposição de cláusulas abusivas ou da publicidade enganosa. 
Na opinião de Paulo Luiz Netto Lôbo (2003, p. 15), "o princípio da função social determina que os interesses individuais das partes do contrato sejam exercidos em conformidade com os interesses sociais, sempre que estes se apresentarem".

Salienta, ainda, o autor (LÔBO, 2003, p. 15), que o Código de 2002, assim como o Código de Defesa do Consumidor, faz da funcionalização do contrato a fins sociais um paradigma no equilíbrio de interesses individuais e sociais, de acordo com os fundamentos especificados pelas Constituições do Estado social.

Segundo Rogério Ferraz Donnini (2000, p. 73-74), a função social do contrato está intimamente ligada à ideia de comutatividade ou justiça comutativa, a partir do momento em que visa impedir a celebração de pactos contrários aos ideais de justiça. Ainda de acordo com a posição do autor, a função social do contrato sempre fez parte da teoria contratual e só não foi utilizada porque se acreditava que poderia ser obtida pela simples atuação dos contraentes, o que não aconteceu de fato.

Carlos Alberto Ghersi (1994, p. 109), ao tratar o fato econômico como causa eficiente ou fonte do contrato, considera que esse fato não deve se produzir de qualquer forma, mas respeitando parâmetros socialmente estabelecidos, que habitualmente se denomina de função social, correspondendo esta a um conceito resultante da aplicação ao campo econômico dos grandes princípios que regem a conduta dos sujeitos de direito, como boa-fé, exercício regular dos direitos, ordem pública econômica etc.

Humberto Theodoro Júnior (2003, p. 55-56), além de destacar a preponderância do interesse coletivo na base da função social do contrato, exemplifica as possibilidades de desvio da função social do contrato, tais como: a) induzir consumidores a adquirirem produto ou serviço sob influência de propaganda enganosa; b) alugar imóvel em zona residencial, para fins comerciais; c) ajustar contrato simulado para prejudicar terceiros; d) disposição de bens em fraude a credores; e) qualquer contrato que importe em concorrência desleal; f) empresa legalmente estabelecida realizar contratos proibidos por lei, como no caso da faturizadora que contrata depósito como se fosse instituição bancária; g) agência de viagens que contrata turismo sexual; e h) qualquer contrato que importe desvio ético ou econômico de finalidade com prejuízo para terceiros.

Todas essas definições utilizam-se de uma contraposição entre interesse individual e interesse social para tentar explicar o significado e delimitar o campo de atuação da função social do contrato. 
Vale lembrar, a esse respeito, o entendimento de Alf Ross (2000, p. 415), para quem toda tentativa de formular um "catálogo" de interesses individuais e sociais conflitantes e independentes está fadado ao fracasso, pois tratam dois aspectos da mesma coisa, o específico e o geral.

Para aclarar seu pensamento, o referido autor (ROSS, 2000, p. 415), afirma, à guisa de exemplo, que aos interesses individuais de possuir objetos materiais, gozar de integridade pessoal, casar-se e formar uma família e celebrar acordos obrigatórios correspondem os interesses sociais numa regulamentação geral da propriedade, da paz, do casamento, da família e dos contratos.

Por essa linha de pensamento, poderíamos afirmar que a inclusão da exigência do respeito à função social do contrato no terreno da regulamentação geral do direito contratual é um reflexo de uma mudança na consciência individual, passando a ser de interesse do indivíduo moderno não apenas a celebração de pactos obrigatórios de forma egoística, mas pactos justos. É para garantir a prevalência dessa visão comum dos indivíduos contra o desvio de alguns, em particular, que se defende a supremacia da faceta que representa o interesse social sobre a faceta individual.

De fato, a característica de proporcionar a supremacia do interesse social sobre o interesse privado não pode ser suficiente para definir a função social dos contratos, tendo em vista que tal característica não é peculiar apenas a este instituto, mas se nota também em outras limitações da autonomia privada, como, por exemplo, no caso dos preceitos de ordem pública, dos bons costumes e até da moral (DAIBERT, 1973, p. 20).

Dentro da visão moderna da função social, outro grupo de autores vai mais longe e, além de ressaltar o caráter da função social de condicionadora do interesse privado ao interesse público, limitando a autonomia privada e o direito de contratar, erige aquele princípio ao patamar de fundamentação de outras limitações à autonomia privada que se apresentam na legislação contratual.

Segundo Antonio Jeová Santos (2002, p. 104), a função social do contrato se caracteriza por inúmeras regras do Código Civil, reprimindo com veemência os atos não socialmente desejados, no intuito de regularizar a conduta das partes à finalidade social dos contratos. Exemplos dessas regras seriam os arts. 171 e 487, do citado Código.

$\mathrm{O}$ art. 171 trata da anulação do negócio por lesão, fundando-se na ideia de que não é socialmente justo permitir-se que um contratante obtenha lucro beneficiando-se da situação de necessidade ou ignorância da outra parte; e o art. 487 trata da resolução contratual por onerosidade excessiva superveniente e parte do princípio de que não é socialmente aceitável ter uma parte lucro em razão de fato imprevisível. 
Tanto no caso do referido art. 171 quanto no caso do art. 487, observa-se que há uma quebra do equilíbrio valorativo entre as prestações contratuais, e, nesses casos, o contrato, como instrumento de intercâmbio econômico, perderia sua utilidade social.

Posicionamento similar sobre o tema, externa Arruda Alvim (2003, p. 100), ao declarar que

\footnotetext{
O mais expressivo significado da função social do contrato é o de que ele se encontra permeado, através de outros textos próprios do Código Civil, dado que julgo que nós não podemos interpretar a função social do contrato que, na verdade, é um valor justificativo da existência do contrato, tal como a sociedade enxerga no contrato um instituto bom para a sociedade.
}

Conforme a opinio do referido autor (ALVIM NETTO, 2003, p. 100), o grande espaço da função social já se observa no próprio Código Civil de 2002, através de outros institutos que amenizam a dureza da visão liberal do contrato.

Nelson Nery Junior (2003, p. 336) também parece compartilhar da mesma visão ao afirmar que "a boa-fé objetiva, cláusula geral prevista no CC 422, decorre da função social do contrato, de modo que tudo o que se disser sobre boa-fé objetiva poderá ser considerado como integrante, também, da cláusula geral da função social do contrato".

Nessa linha de pensamento, Maria Helena Diniz (2002, p. 36) pondera que o referido art. 421 revitaliza o contrato para atender aos interesses sociais, limitando a manifestação de vontade dos contratantes, visando tutelá-los no meio social, criando condições para o equilíbrio econômico-contratual, facilitando a revisão das prestações e até mesmo a resolução do contrato.

Em obra diversa, a referida autora (DINIZ, 2003, p. 322) afirma também que a função social do contrato reforça o princípio da conservação dos contratos, assegurando a efetivação das trocas consideradas justas e úteis.

Já Daniel Martins Boulos (2003, p. 133) destaca que a tutela da função social do contrato como princípio informador de todo o direito contratual não se revela apenas no art. 421, do novo Código civil, mas também em outras tantas normas do Código que podem ser consideradas desdobramentos ou aplicações do referido princípio, como, por exemplo, as normas que atribuem caráter de nulidade relativa aos atos praticados em estado de perigo (art. 156), que disciplinam a lesão (art. 157), que vedam a onerosidade excessiva (arts. 478-480) etc.

Conclui Luiz Guilherme Loureiro (2002, p. 53 e 56) que através da função social do contrato o legislador pretende, sem prejudicar a autonomia da vontade, 
garantir o equilíbrio contratual e proteger o interesse social quando em contraste com o interesse particular, a exemplo do que já ocorria no caso da função social da propriedade, não admitindo a luta contratual desleal, o abuso da superioridade de um dos contratantes, a eliminação da equidade, o abuso do estado de perigo, ou a lesão ao outro contratante.

Diante desse entendimento, do qual compartilhamos, ousamos externar uma compreensão da função social do contrato como um princípio social do contrato, compatibilizando-o com os ideais do Estado social, limitando a autonomia privada e ao mesmo tempo fundamentando outras limitações a essa autonomia, a exemplo do que ocorre no caso do reconhecimento da lesão como vício do consentimento, da boa-fé objetiva e da resolução por onerosidade excessiva, estando a dita função social numa posição hierarquicamente superior a essas outras limitações.

Não resta dúvida de que a função social do contrato nasceu como princípio jurídico, o qual, antes mesmo de ser positivado no art. 421, do Código Civil de 2002, já estava implícito no ordenamento por força das disposições constitucionais que versam sobre função social da propriedade, o caráter social da livre iniciativa etc., fundamentando toda uma nova ordem contratual.

Ao definir os princípios jurídicos, Karl Larenz (1985, p. 32-33) ensina serem estes "los pensamientos directores de una regulación jurídica existente o posible. En sí mismos no son todavía reglas susceptibles de aplicación, pero pueden transformarse en reglas".

Pode-se distinguir uma função ativa e uma função negativa dos princípios. A função positiva consiste na influência exercida nas decisões e no conteúdo de regulamentação que tais decisões criam; a função negativa, na exclusão dos valores a ele contrapostos e das normas que descansam sobre esses valores (LARENZ, 1985, p. 33).

Há princípios que se estendem por todos os campos do Direito, sendo, nesse sentido, fundamentais, e outros têm importância apenas para um determinado campo do Direito (LARENZ, 1985, p. 53). Contudo, o grau de generalidade não é decisivo para que se tenha um princípio, mas, sim, sua atitude como causa de justificação e sua emissão em uma regulamentação ou em várias (LARENZ, 1985, p. 36).

Tendo em vista a natureza de princípio que se manifesta na função social dos contratos, entendemos que esta pode ser alargada para compreender, na verdade, todas as espécies do gênero negócio jurídico, independentemente de haver previsão específica sobre o assunto nessa seara.

Note-se que, com base na ideia de função social dos contratos como um instrumento que impede que o negócio se desvie do fim pelo qual alcançou a 
aceitação e difusão no meio social, mantendo-se, de fato, útil para a comunidade, pode-se afirmar que resta englobada a proteção à causa do negócio jurídico vislumbrada em países como França e Itália, os quais, inclusive, não fazem menção exata à expressão "função social do contrato".

Por meio da função social, é possível se atingir o controle do objeto dos pactos, através da intervenção social no mesmo, bloqueando-se o liberalismo e o individualismo exacerbados e patológicos, o que se perfaz no mesmo objetivo pretendido pelos países que adotaram a corrente causalista em suas legislações sobre o tema negócio jurídico.

\section{CONCLUSÃ̃}

Diferentemente do que se nota no Código Civil italiano, art. 1.325, e no francês, art. 1.108, o Direito pátrio não consagra a causa objetiva como elemento do negócio jurídico, não se verificando qualquer referência legislativa a esse respeito no Código Civil, de onde se conclui que o Brasil adotou, quanto ao assunto, a corrente anticausalista.

Embora o termo causa seja de difícil conceituação, devido a sua abstração, não se deve confundir os termos "causa" e "motivo" do negócio jurídico, sendo que o Código Civil é expresso, no seu art. 140, ao determinar que este não interfere no contrato, a menos que esteja assim consignado expressamente como razão determinante do mesmo.

A causa não se confunde, ainda, com o que Antonio Junqueira de Azevedo (2008, p. 150) denomina de elemento categorial inderrogável objetivo, sendo que este sim é integrante da estrutura do negócio e fixa o regime jurídico a que o negócio obedece.

Embora se constate a ausência da referência à causa pelo legislador pátrio no que se refere ao negócio jurídico, isso não significa que, de forma diversa, o ordenamento nacional não contenha norma a instrumentalizar a proteção nesse sentido, como se constata, por exemplo, no princípio da função social dos contratos, materializado no art. 421, do Código Civil.

A função social viabiliza o controle dos pactos, através da intervenção social nessa seara, bloqueando-se, assim, o liberalismo e o individualismo exacerbados e patológicos, o que se perfaz no mesmo objetivo pretendido pelos países que adotaram a corrente causalista em suas legislações sobre o tema negócio jurídico.

Em suma, causalistas e anticausalistas adeptos da função social dos contratos se avizinham no discurso de que os negócios não podem corresponder 
a um instrumento de satisfação pessoal das partes ou simplesmente de desenvolvimento econômico, devendo-se observar o seu papel social, ou seja, de que forma contribuem para o desenvolvimento da sociedade, sendo dotados, assim, de cognoscibilidade social.

Consubstanciando-se o princípio da função social dos contratos em um instrumento a obstar que o negócio se desvie do fim pelo qual se tornou reconhecido, difundido e útil perante a sociedade, é possível concluir que resta, por tal via, perfeitamente englobada a proteção à causa do negócio jurídico no Direito brasileiro.

\section{REFERÊNCIAS}

ALBALADEJO, Manuel. El negocio jurídico. Barcelona: Bosch, 1958.

ALTERINI, Atilio Aníbal. Contratos: teoría general. Buenos Aires: Abeledo-Perrot, 1999.

ALVIM NETTO, José Manoel de Arruda. A função social dos contratos no novo Código Civil. In: PASINI, Nelson et al. (Coord.). Simpósio sobre o novo Código Civil brasileiro. São Paulo: Método/Banco Real, 2003. p. 75-102.

AMARAL, Francisco. Direito Civil: introdução. 7. ed. rev. e aum. Rio de Janeiro: Renovar, 2008. ASCENSÃO, José de Oliveira. Direito Civil: teoria geral - ações e fatos jurídicos. 3. ed. São Paulo: Saraiva, 2010. v. 2.

AZEVEDO, Álvaro Villaça. Teoria geral dos contratos típicos e atípicos. São Paulo: Atlas, 2002.

AZEVEDO, Antônio Junqueira de. Negócio jurídico: existência, validade e eficácia. 4. ed. atual. São Paulo: Saraiva, 2008.

Princípios do novo direito contratual e desregulamentação do mercado: direito de exclusividade nas relações contratuais de fornecimento - função social do contrato e responsabilidade aquiliana do terceiro que contribui para inadimplemento contratual. Revista dos Tribunais, São Paulo, a. 87, v. 750, p. 113-120, abr. 1998.

BETTI, Emilio. Teoria geral do negócio jurídico. Campinas: Servanda, 2008.

BONAVIDES, Paulo. Do Estado liberal ao Estado social. 3. ed. Rio de Janeiro: FGV, 1972.

BOULOS, Daniel Martins. A autonomia privada, a função social do contrato e o novo Código Civil. In: ALVIM, Arruda et al. (Coord.). Aspectos controvertidos do novo Código Civil. São Paulo: Revista dos Tribunais, 2003. p. 125-136.

CARBOnNIER, Jean. Droit Civil: les biens, les obligations. Paris: Quadrige/PUF, 2004. v. 2.

CHAVES, Antônio. Tratado de Direito Civil: parte geral. 3. ed. São Paulo: Revista dos Tribunais, 1982. v. I, t. II.

CIFUENTES, Santos. Negocio jurídico: estrutura - vícios - nulidades. Buenos Aires: Astrea, 1986.

DAIBERT, Jefferson. Dos contratos. Rio de Janeiro: Forense, 1973.

DE PLÁCIDO E SILVA. Vocabulário jurídico. Rio de Janeiro: Forense, 1963. v. II. 
DÍEZ-PICAZO, Luis; GULLÕN, Antonio. Instituciones de Derecho Civil: introducción, parte general, derecho de la persona. 2. ed. Madrid: Tecnos, 2000. v. I/1.

DINIZ, Maria Helena.Código Civil anotado. 9. ed. rev., atual. e ampl. São Paulo: Saraiva, 2003. Curso de Direito Civil brasileiro: teoria das obrigações contratuais e extracontratuais. 17. ed. São Paulo: Saraiva, 2002. v. 3.

Curso de Direito Civil brasileiro: teoria geral do Direito Civil. 28. ed. São Paulo: Saraiva, 2011. v. 1.

Teoria do negócio jurídico, 27 ago. 2009. Notas de aula ministrada na PUCSP, no curso de pós-graduação (doutorado), mimeografado.

DONNINI, Rogério Ferraz. A Constituição Federal e a concepção social do contrato. In: VIANA, Rui Geraldo Camargo; NERY, Rosa Maria de Andrade (Org.). Temas atuais de Direito Civil na Constituição Federal. São Paulo: Revista dos Tribunais, 2000. p. 69-79.

FIÚZA, César. Direito Civil: curso completo. 13. ed. rev., atual. e ampl. Belo Horizonte: Del Rey, 2009.

GHERSI, Carlos Alberto. Contratos civiles y comerciales: partes general y especial. 3 ed. atual. e ampl. Buenos Aires: Astrea, 1994.

GUEDES, Jefferson Carús. Função social das "propriedades": da funcionalidade primitiva ao conceito atual de função social. In: ALVIM, Arruda et al. (Coord.). Aspectos controvertidos do novo Código Civil. São Paulo: Revista dos Tribunais, 2003.

GOMES, Orlando. Contratos: atualizado por Humberto Theodoro Júnior. 25. ed. Rio de Janeiro: Forense, 2002.

Introdução ao Direito Civil. 20. ed. rev., atual. e aum. Rio de Janeiro: Forense, 2010.

Transformações gerais do direito das obrigações. São Paulo: Revista dos Tribunais,

1967.

GORLA, Gino. El contrato (Il contratto). Tradução de José Ferrandis Vilella. Barcelona: Bosch, 1959.

HeDEMman, J. W. Tratado de Derecho Civil: derecho de obligaciones. Tradução de José Luis Diez Pastor y Manuel Gonzalez Enriquez. Madrid: Revista de Derecho Privado, 1958. v. III.

JORGE JÚNIOR, Alberto Gosson. Direto dos contratos. São Paulo: Saraiva, 2013.

LARENZ, Karl. Derecho Civil: parte general. Tradução de Miguel Izquierdo y Macías-Picavea. Madrid: Revista de Derecho Privado, 1978.

Derecho justo. Trad. Luis Díez-Picazo. Madrid: Civitas, 1985.

LÔBO, Paulo Luiz Netto. Princípios contratuais. In: LÔBO, Paulo Luiz Netto; LYRA JÚNIOR, Eduardo Messias Gonçalves de (Coord.). A teoria do contrato e o novo Código Civil. Recife: Nossa Livraria, 2003. p. 9-23.

LORENZETTI, Ricardo Luis. Tratado de los contratos. Buenos Aires: Rubinzal-Culzoni, 1999. t. I.

LOUREIRO, Luiz Guilherme. Teoria geral dos contratos no novo Código Civil. São Paulo: Método, 2002.

MESSINEO, Francesco. Manuale di Diritto Civile e Commerciale. 9. ed. riveduta e aggiornata. Milano: Dott. A. Giuffrè, 1957. v. 1.

MONTEIRO, Washington de Barros; PINTO, Ana Cristina de Barros Monteiro França. Curso de Direito Civil: parte geral. 42. ed. São Paulo: Saraiva, 2009. v. 1. 
NERY JUNIOR, Nelson; NERY, Rosa Maria de Andrade. Código Civil anotado e legislação extravagante. 2. ed. rev. e ampl. São Paulo: Revista dos tribunais, 2003.

PEREIRA, Caio Mário da Silva. Instituições de Direito Civil: introdução ao Direito Civil - teoria geral de Direito Civil. 20. ed. rev. e atual. Rio de Janeiro: Forense, 2004. v. I.

RÁO, Vicente. Ato jurídico. São Paulo: Max Limonad, 1961.

REALE, Miguel. Lições preliminares de Direito. 27. ed. atual. São Paulo: Saraiva, 2002.

RODRIGUES, Silvio. Dos vícios do consentimento. 3. ed. atual. São Paulo: Saraiva, 1989.

ROSS, Alf. Direito e justiça.Trad. Edson Bini. Bauru: Edipro, 2000.

RUGGIERO, Roberto de. Instituições de Direito Civil. 6. ed. Tradução de Paolo Capitanio Campinas: Bookseller, 1999. v. I.

SANTOS, Antonio Jeová. Função social, lesão e onerosidade excessiva nos contratos. São Paulo: Método, 2002.

THEODORO JÚNIOR, Humberto. O contrato e sua função social. Rio de Janeiro: Forense, 2003.

TRABUCCHI, Alberto. Instituiciones de Derecho Civil. Madrid: Revista de Derecho Privado, 1967. v. I. 